\title{
Effect of Milk Productive Seasons on Prolactin Hormone, Milk Composition and Metabolites in the Blood of Local Cows
}

\author{
Talib A. H. Al. Rubaei Hadeel A. Ebid Bassim K. Ebrahim \\ AL-Furat AL-Awat Technical University Babylon, Iraq, AL-Musaib Technical \\ College.
}

talibahmed733@gmail.com

\begin{abstract}
The study was conducted in private fields in Babylon province, to study the effect of milk productive seasons on Prolactin hormone, milk composition and metabolites in the blood of local cows. The study included 24 dairy cows during the second, third and fourth milk seasons. The results showed that the milk season was a significant effect $(\mathrm{p}<0.05)$ on the concentration of the prolactin hormone, fat, lactose and non- fat solids (SNF) of milk. There was non significant effect of the milk season in metabolic concentrations (glucose, total cholesterol and total protein).

The results of the study showed a positive correlation between prolactin hormone, lactose and SNF and a significant positive correlation $(\mathrm{p}<0.01)$ between prolactin hormone and fat and SNF of milk and high correlation $(\mathrm{p}<0.01)$ between the milk season and prolactin and significant correlation $(\mathrm{p}<0.05)$ between prolactin hormone and total cholesterol. We conclude from this study that the milk season has an effect on milk hormone and a link between milk hormone, milk components and metabolic substances in the blood.
\end{abstract}

Keywords: Cows, Milk, Milk hormone, Metabolic substances 


\title{
تأثير مواسر إنتاج الحليب فيخ هرمون الحليب (Prolactin) ومكونات الحليب والمواد
}

\section{الإيظية فهي الدم للإبقار المحلية}

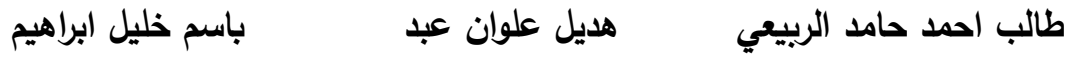 \\ قسم الإنتاج الحيواني , الكلية التقنية / المسيب , جامعة الفرات الاوسط التقنية
}

الخلاصة

أجريت الدراسة في حقول أهلية في محافظة كربلاء المقدسة، لدراسة تأثير مواسم إنتاج الحليب في هرمون الحليب (Prolactin)

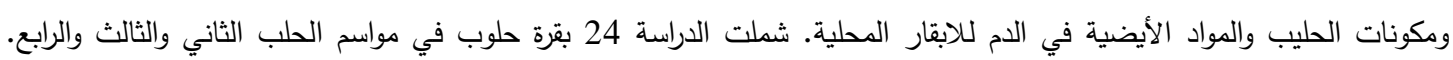

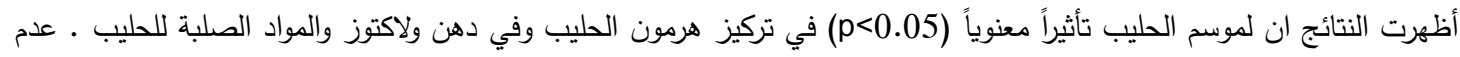

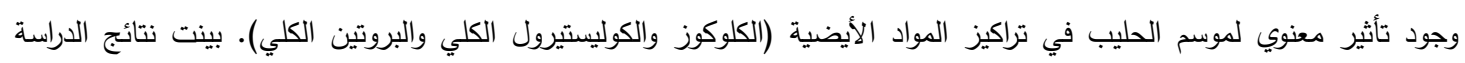

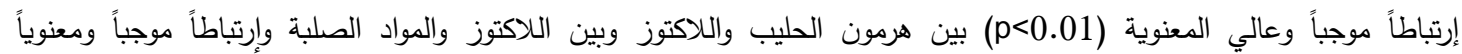

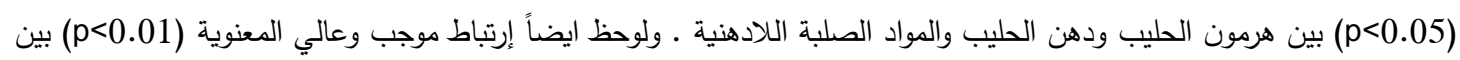

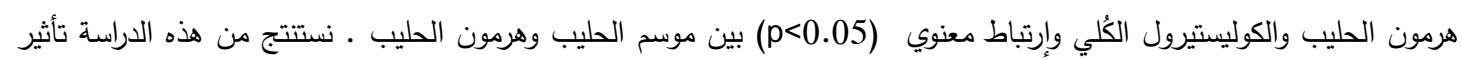

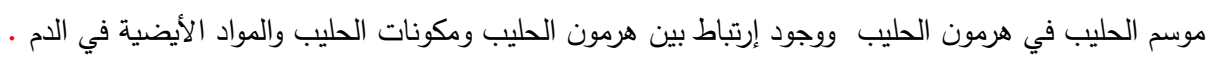
الكلمات الادالة: الأبقار , الحليب , هرمون الحليب , المواد الأيضية .

\section{المقدمة}

تُعد الأبقار من الحيوانات الرئيسة لإنتاج الحليب في معظم بُلدان العالم مع الجاموس والأغنام والماعز ،

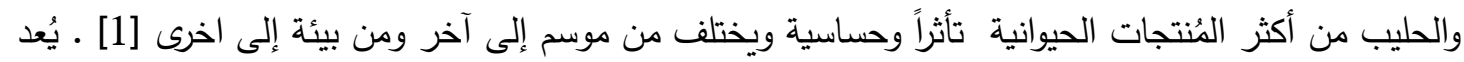

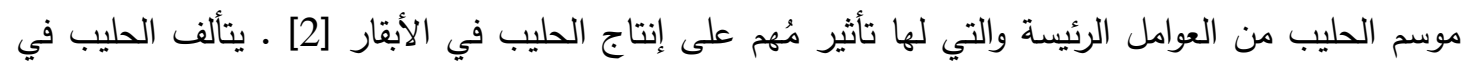

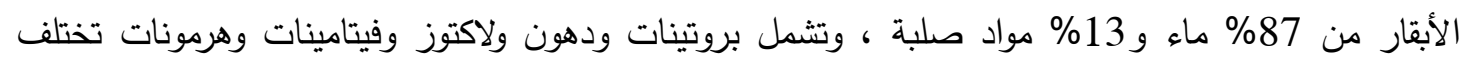

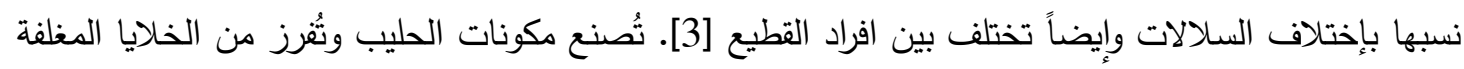

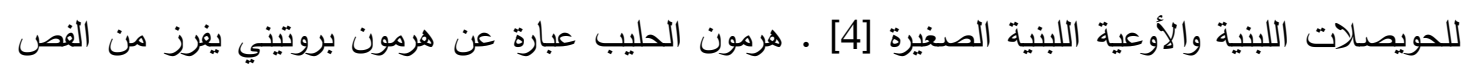

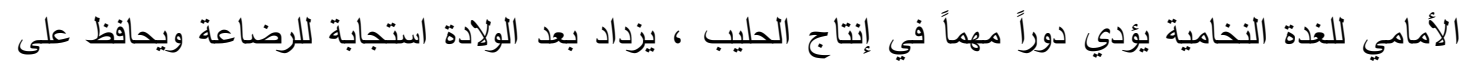

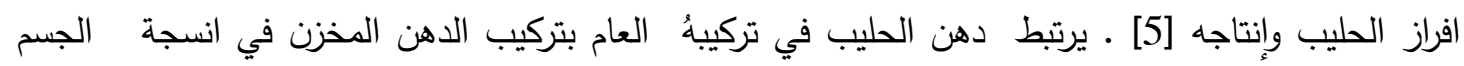

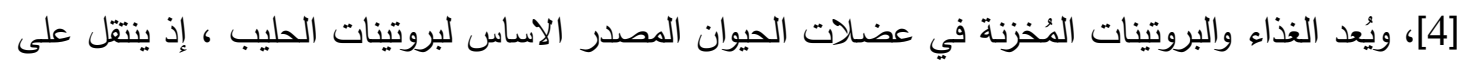

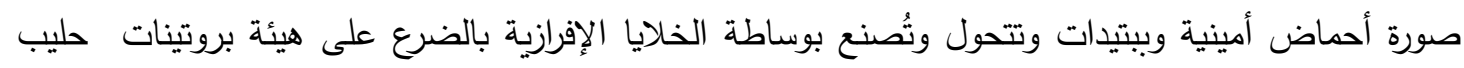

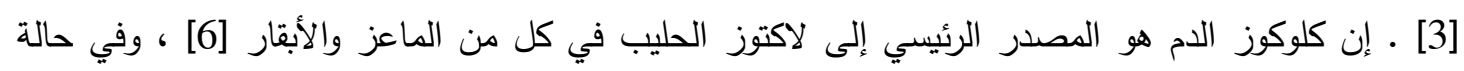

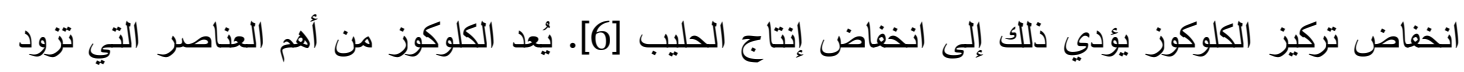

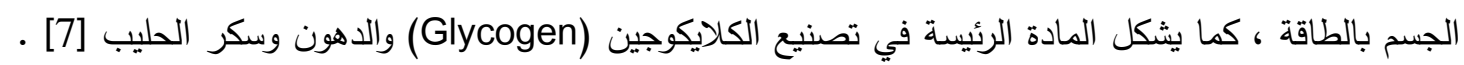

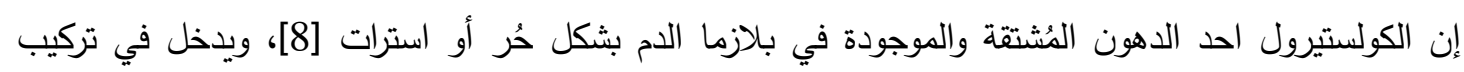

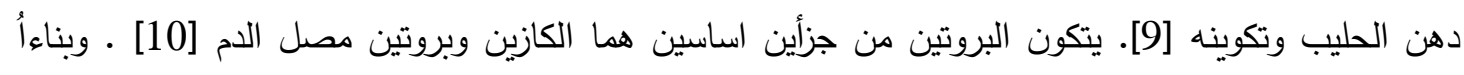

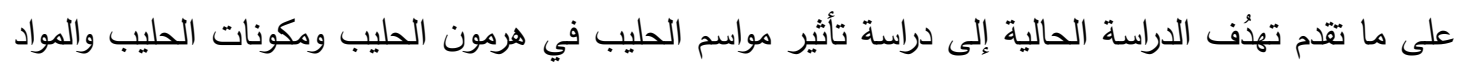
الأيضية في دم الأبقار المحلية. 


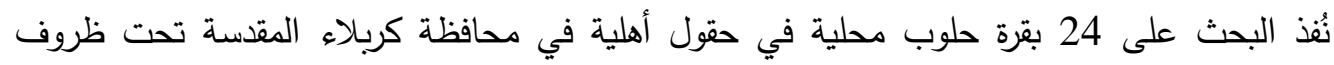

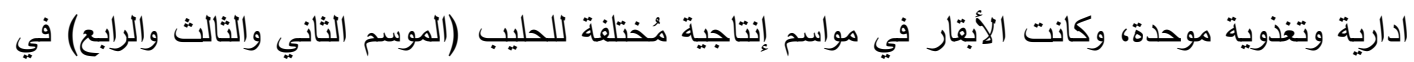
مراحل عمرية مختلفة (4-2) سنوات. اخذت عينات الحليب من الأبقار صباحاً كل اسبوع للمدة من تشرين الاول ولغاية كانون الاول 2017 , وحُفظ الحليب في أنابيب بلاستيكية نظيفة لحين وصولها إلى المختبر

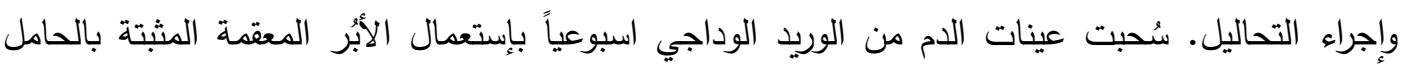

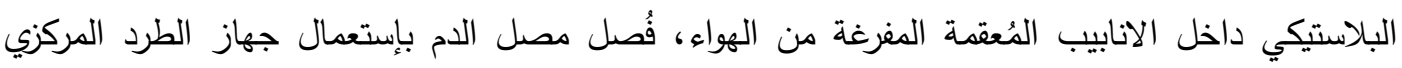

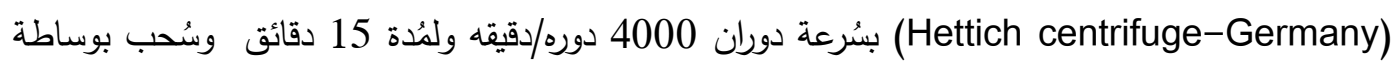

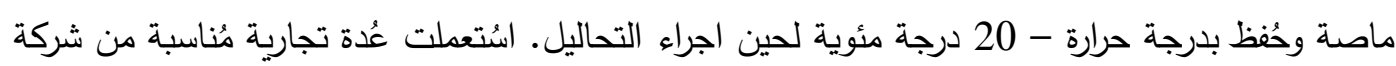
لتقدير تركيز الكلوكوز والكوليستيرول الكلي والبروتين الكلي وبوساطة (Agappe Kit , Switzerland)

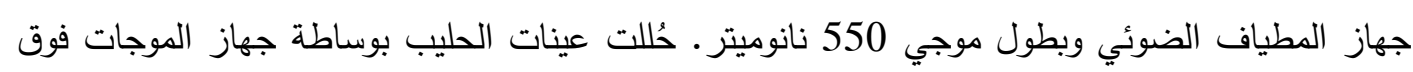
الصوتية نوع (Lacto Flash- Germany) في مُختبر الفسلجة التابع لِقسم تقنيات الإنتاج الحيواني في لئي الكُلية التقنية/ المسيب, حُضرت عينة الحليب (10 مليليتر) بدرجة حرارة الغرفة وجُنست قبل إدخالها للجهاز

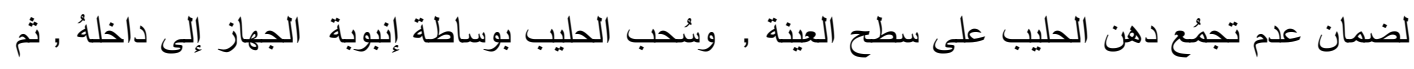
بدأ بقراءة مُكونات الحليب رقمياً (نتائج التحليل) والتي تشمل نسبة الدهن والبروتين واللاكتوز والمواد الصلبة اللادهنية والكثافة .

\section{التحليل الاحصائي}

إستعمل برنامج (CPSS) (11) باعتماد التصميم العشوائي الكامل (CRD) لتحليل بيانات التجربة كما

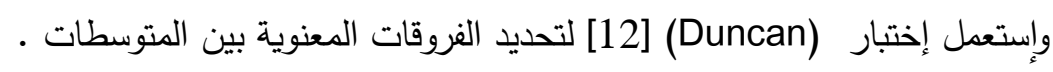

\section{النتائج وإلمناقشة}

يبين الجدول 1 أن لموسم إنتاج الحليب تأثيراً معنوياً (p0.05>p) في تركيز هرمون الحليب في مواسم

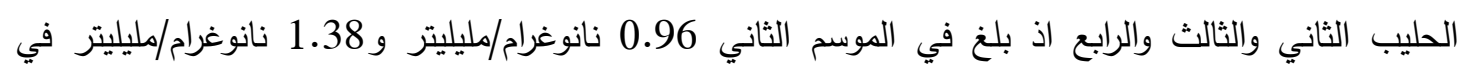
الموسم الثالث وفي الموسم الرابع 2.28 نانوغرام/مليليتر، أن هذه الزيادة التدريجية في تركيز هرمون الحليب

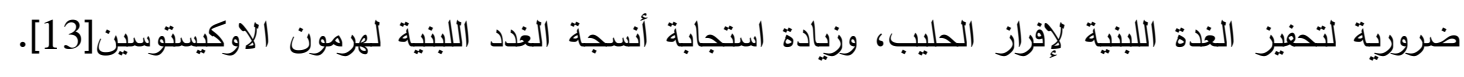
يزداد إنتاج الحليب بتقدم موسم الحليب إذ تصل قمة الإنتاج في الموسم الرابع ويعود ذلك إلى الزيادة في حجم

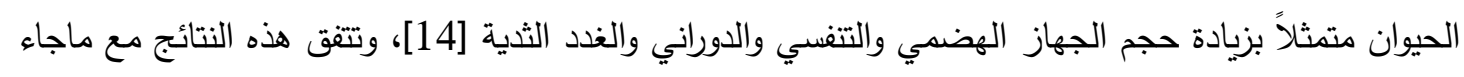
به [ 15] إذ بين أن هناك إرتباط بين تركيز هرمون الحليب وإنتاج الحليب ، ولايتفق مع [16] اذ بين ولين ان تركيز

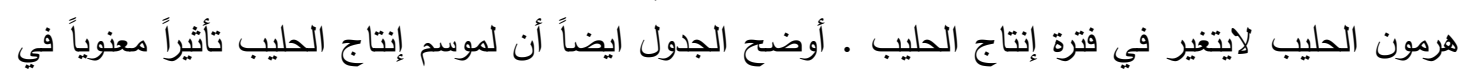

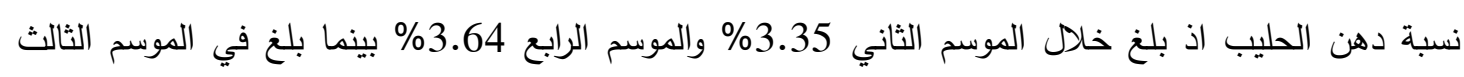
2.69\% قد يكون سببه النقص في مخزون دهن الجسم ووجود علاقة سالبة بين إنتاج الحليب ونسبة الدهن فيه [3]، تتفق هذه النتائج مع [2] في ابقار الفريزيان الذي بين وجود تأثير معنوي لموسم إنتاج الحليب في نسبة 
الدهن، عدم وجود تأثير معنوي لموسم الحليب في نسبة بروتين الحليب اذ بلغ 2.75\% في الموسم الثاني

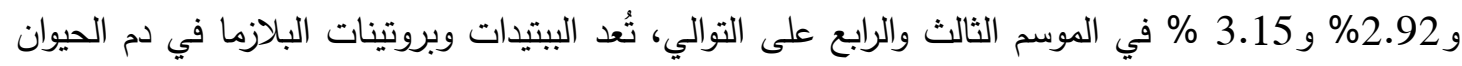

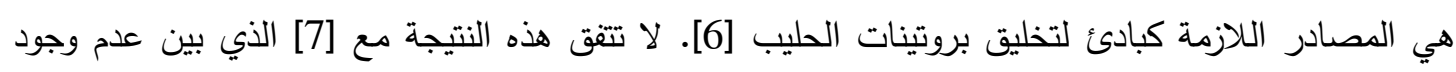
تأثير معنوي لموسم الحليب في نسبة البروتين ، هذا الإختلاف قد يكون بسبب سلالة الحيوان والموقع الجغرافي

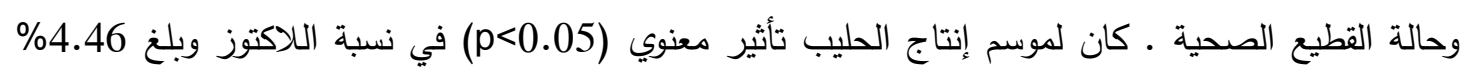

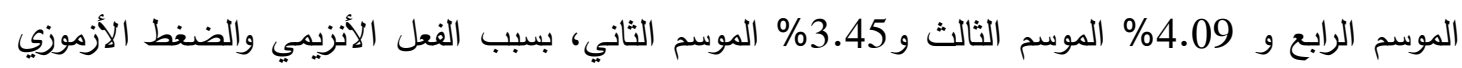
للسكريات المتعددة وتحويلها إلى سكر اللاكتوز [2]، لا تتفق هذه النتيجة مع [2] الذي بين عدم وجود تأثير التير

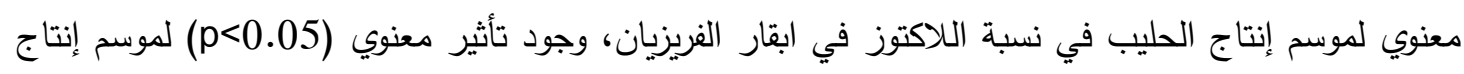

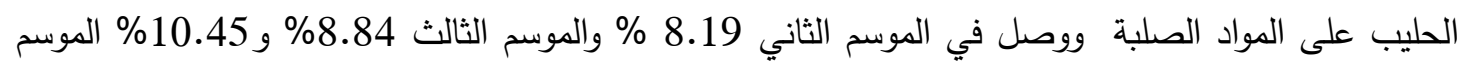

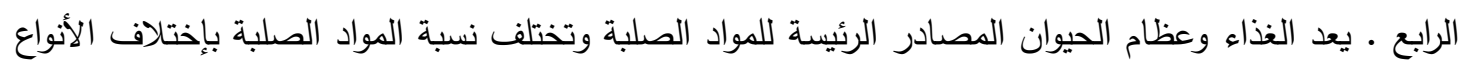

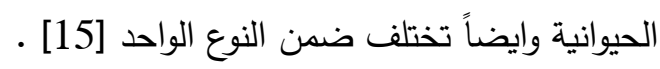

جدول 1. تركيز هرمون الحليب ومكونات الحليب في مواسم الحليب (المتوسط د الخطأ القياسي)

\begin{tabular}{|c|c|c|c|c|c|}
\hline \multicolumn{5}{|c|}{ المتوسط د الخطأ القياسي } & \multirow{2}{*}{ موسم الحلب } \\
\hline المواد الصلبة & اللاكتوز \% \% & بروتين الحليب \% & دهن الحليب \% & نانوغرام / مليليتر & \\
\hline $\begin{array}{c}0.35 \pm 8.19 \\
B\end{array}$ & $\begin{array}{c}0.22 \pm 3.45 \\
\mathrm{~B} \\
\end{array}$ & $\begin{array}{c}0.18 \pm 2.75 \\
\mathrm{~A} \\
\end{array}$ & $\begin{array}{c}0.21 \pm 3.35 \\
\mathrm{~A} \\
\end{array}$ & $\begin{array}{c}\mathbf{0 . 1 4} \pm 0.96 \\
\mathrm{C}\end{array}$ & الثاني \\
\hline $\begin{array}{c}0.41 \pm 8.84 \\
\text { B }\end{array}$ & $\begin{array}{c}0.45 \pm 4.09 \\
\mathrm{~A}\end{array}$ & $\begin{array}{c}0.26 \pm 2.92 \\
\text { A }\end{array}$ & $\begin{array}{c}0.29 \pm 2.69 \\
\text { B }\end{array}$ & $\begin{array}{c}\mathbf{0 . 1 1} \pm 1.38 \\
\text { B }\end{array}$ & الثالث \\
\hline $\begin{array}{c}\mathbf{0 . 5 0} \pm \mathbf{1 0 . 4 5} \\
\mathrm{A}\end{array}$ & $\begin{array}{c}0.52 \pm 4.46 \\
\mathrm{~A} \\
\end{array}$ & $\begin{array}{c}0.52 \pm 3.15 \\
\mathrm{~A} \\
\end{array}$ & $\begin{array}{c}0.38 \pm 3.64 \\
\mathrm{~A}\end{array}$ & $\begin{array}{c}0.17 \pm 2.28 \\
\mathrm{~A} \\
\end{array}$ & 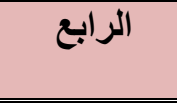 \\
\hline$(\mathrm{P}<0.05)$ & $(\mathrm{P}<0.05)$ & غير معنوي & $(\mathrm{P}<0.05)$ & $(\mathrm{P}<0.05)$ & المعنوية \\
\hline
\end{tabular}

بينت نتائج الجدول 2 عدم وجود تأثير معنوي لموسم الحليب في تركيز الكلوكوز وبلغ في الموسم الثاني والثالث

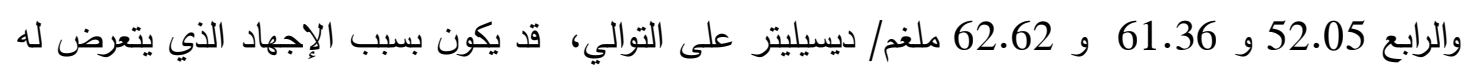

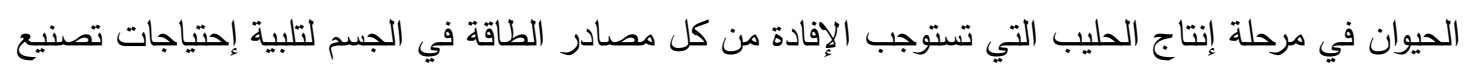

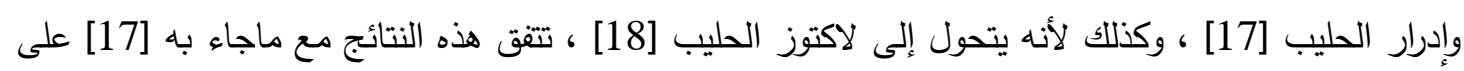

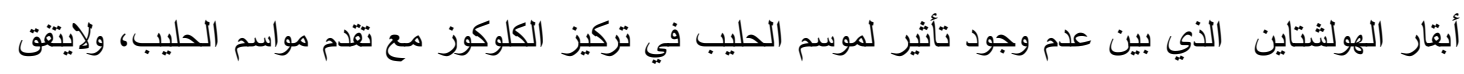

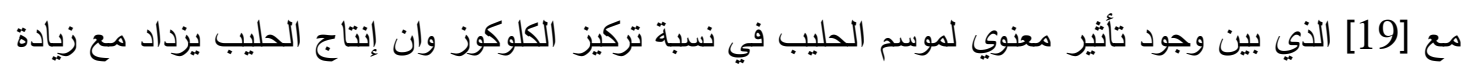

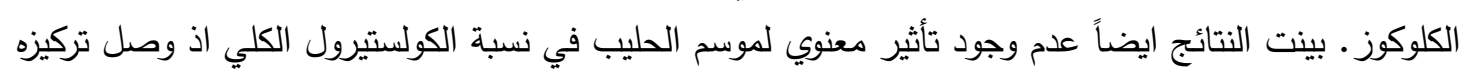

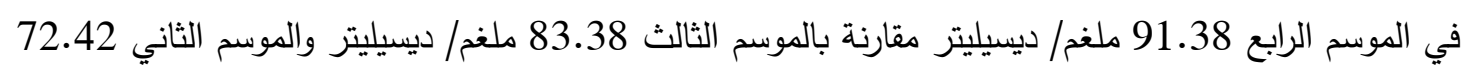

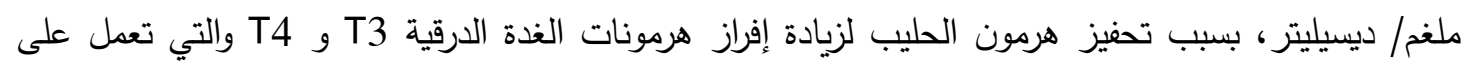


اكسدة الكوليسترول وتقليل نسبته في الدم [20]، وبسبب زيادة امتصاص الكولستيرول بوساطة الإنسجة المعقدة

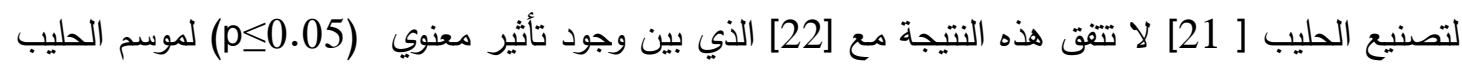
في نسبة تركيز الكوليسترول في الماعز الإسود الجبلي قد يكون بسبب إختلاف نوع الحيوان والمنطقة الجغرافية ونوعية التغذية. عدم وجود تأثير معنوي لموسم الحليب في نسبة البروتين الكلي وصل تركيزه في الموسم الثاني

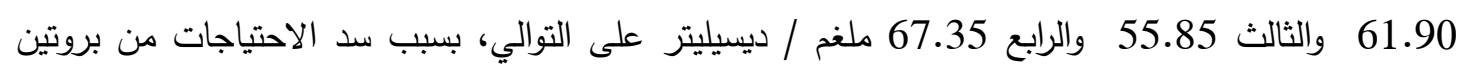
الحليب في مرحلة إنتاج الحليب [ 23] ، يتغير تركيز البروتين في مرحلة إنتاج الحليب اذ يؤدي دوراً مهماً في من في

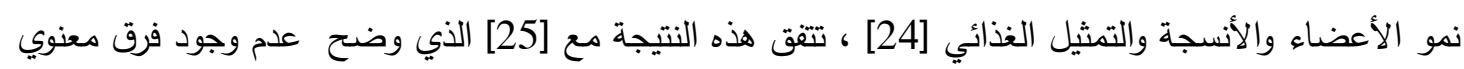
لتأثير موسم الحليب على نسبة البروتين الكلي.

جدول 2 تراكيز المواد الأيضية في مواسم الحليب

\begin{tabular}{|c|c|c|c|}
\hline \multicolumn{3}{|c|}{ المتوسط 土 الخطأ القياسي } & \multirow{2}{*}{ موسم الحليب } \\
\hline البروتين الكلي ملفم/ & الكولستيرول الكلي ملغم/ & ملفم/ديسيليتر & \\
\hline A $\quad 3.99 \pm 61.90$ & A $\mathbf{9 . 7 8} \pm 72.49$ & A $4.80 \pm 52.05$ & الثاني \\
\hline A $\mathbf{5 . 4 5} \pm \mathbf{5 5 . 8 5}$ & A $\quad 8.01 \pm 83.38$ & A $5.60 \pm 61.36$ & الثالث \\
\hline A $\quad 6.02 \pm 67.35$ & A $\quad 8.89 \pm 91.38$ & A $6.79 \pm 62.62$ & الرابع \\
\hline غير معنوي & غير معنوي & غير معنوي & مستوى المعنوية \\
\hline
\end{tabular}

أوضحت نتائج الجدول 3 وجود وجود إرتباط موجب وغير معنوي بين هرمون الحليب ودهن الحليب

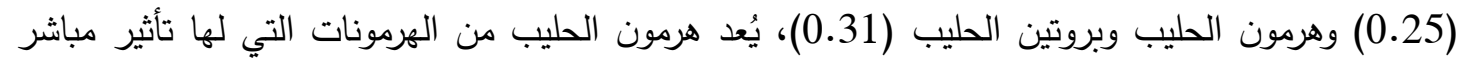

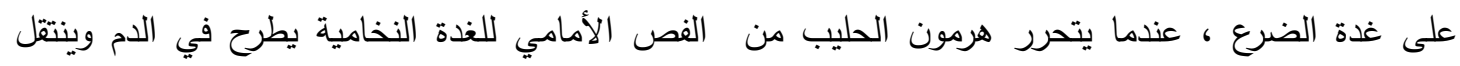

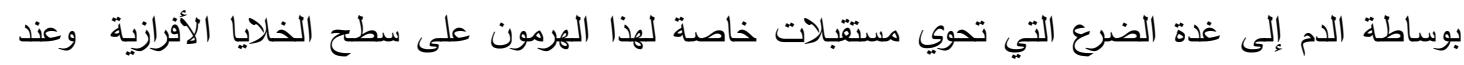
إرتباطه بهذه المستقبلات تستجيب الخلايا الأفرازية منتجة بعض مكونات الحليب مثل بروتين الحليب ودهن

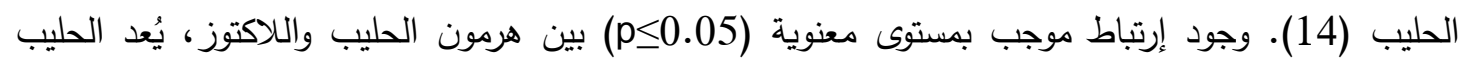

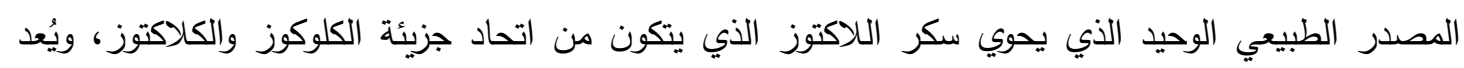

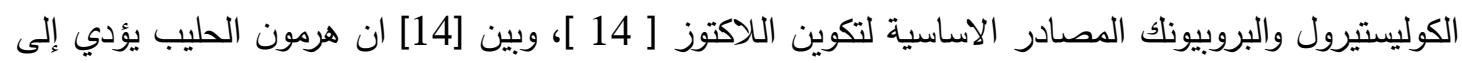
سلسلة من التفاعلات الخلوية ضدن سايتوبلازم الخلايا الافرازية في غدة الضرع مؤدية بالنتيجة إلى تكوين

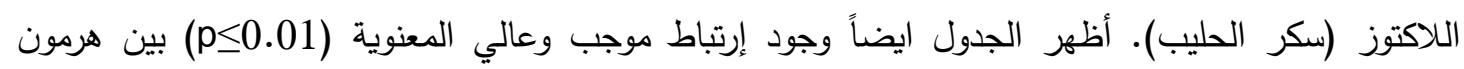


الحليب والمواد الصلبة، لاتمتلك غدة الضرع القدرة على صناعة اغلب المواد الصلبة الموجودة في الحليب اذ

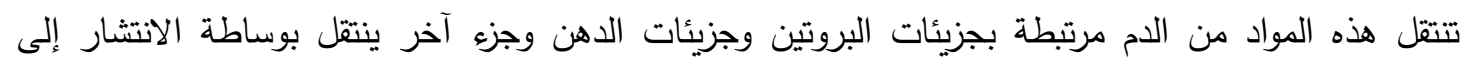

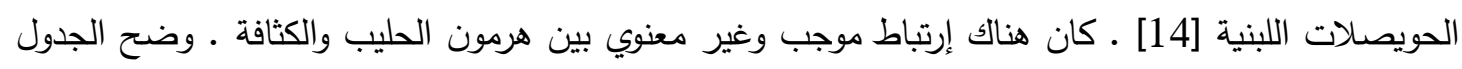
ايضاً وجود إرتباط موجب وغير معنوي بين دهن الحليب وبروتين الحليب واللاكتوز وبمعامل إرتباط بلغ (0.39)

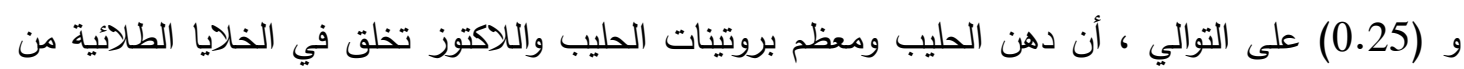
بوادئ تاخذها من الدم ثم تفرز هذه المركبات في فجوات الحويصلات اللبنية وان كمية هذه المركبات تتغير طبقاً

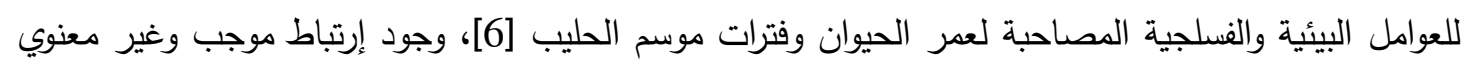

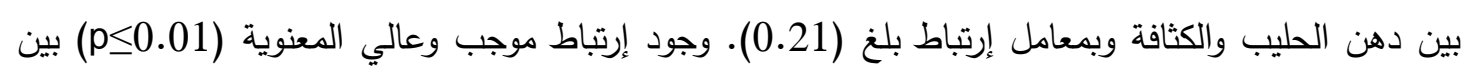
دهن الحليب والمواد الصلبة وبمعامل إرتباط بلغ (0.71)، يُعد الدهن اهم مركبات الحليب ويتأثر سريعاً بعامل

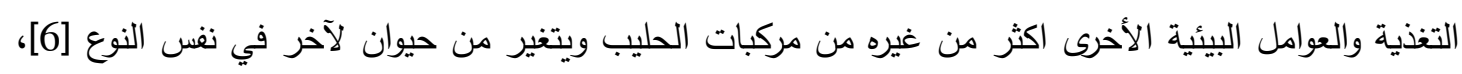

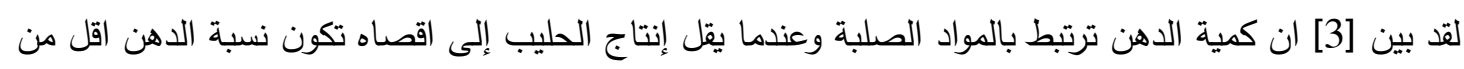

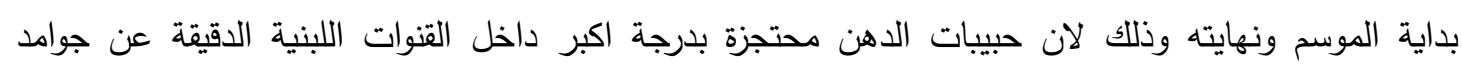

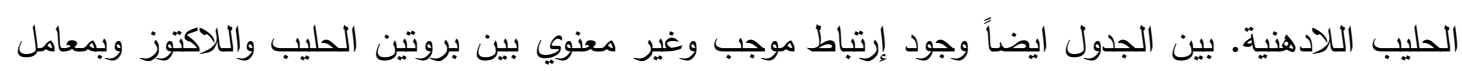

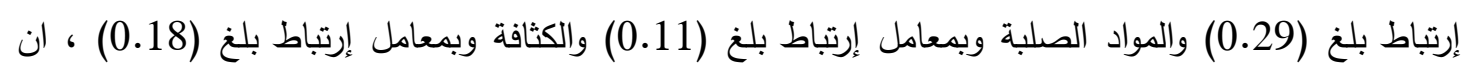

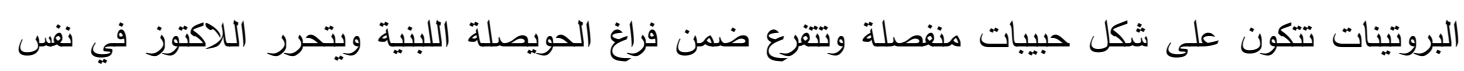

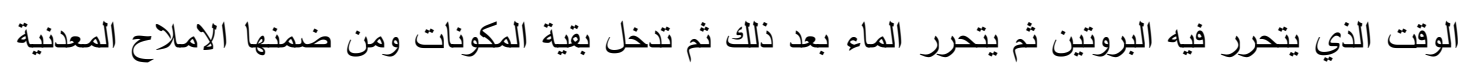

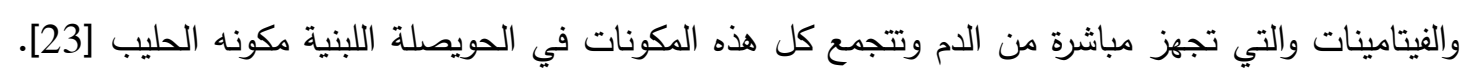
وجود إرتباط موجب ومعنوي بمستوى معنوية (p>0.05) بين اللاكتوز والمواد الصلبة وبمعامل إرتباط بلغ

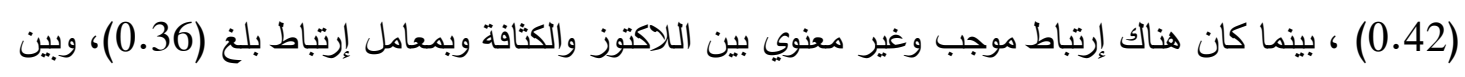

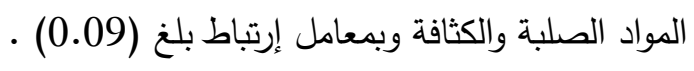

جدول 3 معامل الإرتباط بين هرمون الحليب ومكونات الحليب

\begin{tabular}{|c|c|c|}
\hline مستوى المعنوية & معامل الإرتباط (r) & الصفات المرتبطة \\
\hline غير معنوي & 0.25 & هرمون الحليب ودهن الحليب \\
\hline غير معنوي & 0.31 & هرمون الحليب وبروتين الحليب \\
\hline$(p<0.01)$ & 0.58 & هرمون الحليب واللاكتوز \\
\hline$(p<0.05)$ & 0.77 & هرمون الحليب والمواد الصلبة \\
\hline غير معنوي & 0.05 & هرمون الحليب والكثافة \\
\hline غير معنوي & 0.39 & دهن الحليب وبروتين الحليب \\
\hline غير معنوي & 0.25 & دهن الحليب واللاكتوز \\
\hline$(p<0.05)$ & 0.71 & دهن الحليب والمواد الصلبة \\
\hline
\end{tabular}


Journal of University of Babylon, Pure and Applied Sciences, Vol.(27), No.(1): 2019

\begin{tabular}{|c|c|c|}
\hline غير معنوي & 0.21 & دهن الحليب والكثافة \\
\hline غير معنوي & 0.29 & بروتين الحليب والللاكتوز \\
\hline غير معنوي & 0.11 & بروتين الحليب والمواد الصلبة \\
\hline غير معنوي & 0.18 & بروتين الحليب والكثافة \\
\hline$(p<0.01)$ & 0.42 & اللاكتوز والمواد الصلبة \\
\hline غير معنوي & 0.36 & اللاكتوز والكثافة \\
\hline غير معنوي & 0.09 & المواد الصلبة والكثافة \\
\hline
\end{tabular}

اظهرت نتائج الجدول 4 إرتباط موجب وعالي المعنوية (p<0.05) بين موسم الحليب وهرمون الحليب، بين [26] تأثير هرمون الحليب الذي يزداد بزيادة مواسم الحليب و زيادة إنتاج الحليب، بسبب تطور وكبر حجم

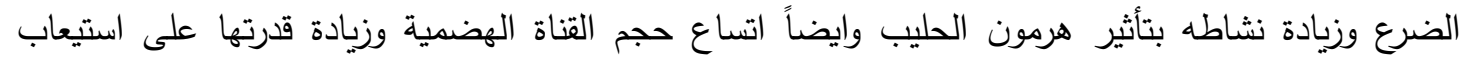
كميات كبيرة من المواد العلفية بتقدم عمر البقرة، بالمقارنة مع مواسم الحلب الأولى بسبب انخفاض أنسجة الضرن الضرع الإفرازية وعدم اكتمال نموها. بين الجدول وجود إرتباط موجب وبمعامل إرتباط بلغ (0.32) وغير معنوي بين موني هرمون الحليب والكلوكوز، ان الكلوكوز مصدر لتكوين لاكتوز الحليب والكلوكوز يستهلك للاستفادة من كل

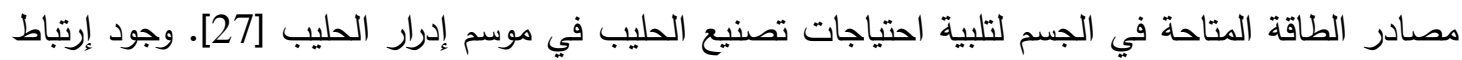
موجب (0.43) ومعنوي بمستوى معنوية (p<0.05) بين هرمون الحليب والكوليستيرول الكلي، وجود إرتباط بين إنتاج الحليب وتركيز الكوليستيرول [28]، يتم استهلاك الكوليستيرول الكلي وتحليله كيميائياً وتحويله إلى الثكل الحر الذي يدخل في تصنيع الهرمونات الثحمية (الاستروجين والبروجسترون) [29]، يشترك هرمون الاستروجين مع هرمون الحليب في نمو الغده اللبنية ويساعد على افراز هرمون الحليب من الفص الامامي للغدة النخامية

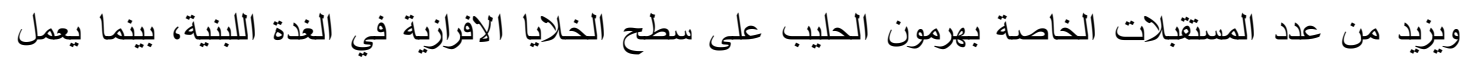
هرمون البروجستيرون على نمو الحويصلات اللبنية داخل الضرع ويشارك في صناعة اللاكتوز [14] و [23]

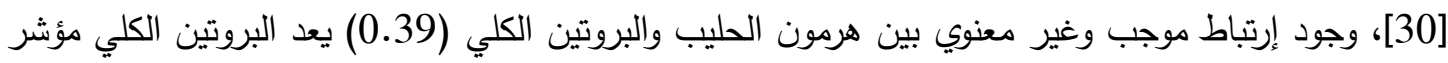
مهم للنشاط الايضي في الحيوانات المنتجة للحليب ويتم استهلاك البروتين في تكوين الحليب و ووجود إرتباط بين

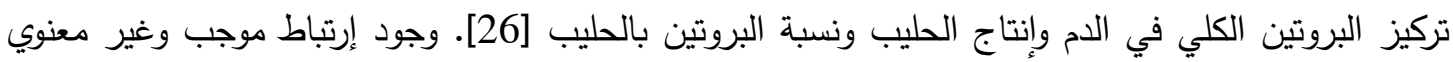
بين الكلوكوز والكولستيرول الكلي والبروتين الكلي (0.25) و (0.09) على التوالي، يتحدد مستوى الكلوكوز في وني

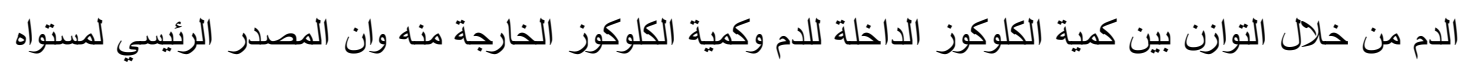

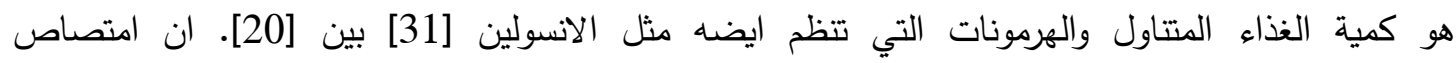

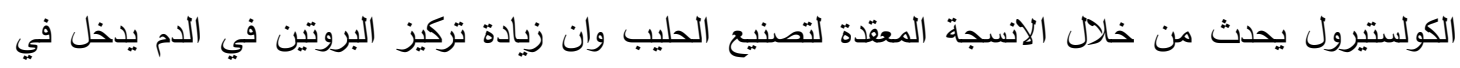
تركيب بروتين الحليب. وجود إرتباط موجب وغير معنوي بين الكولستيرول الكلي والبروتين الكلي (0.28). جدول 4 معامل الإرتباط بين هرمون الحليب وموسم الحليب ومكونات الدام

\begin{tabular}{|c|c|c|}
\hline مستوى المعنوية & معامل الإرتباط (r) & الصفات المرتبطة \\
\hline$\overline{(2 p<0.05)}$ & 0.79 & موسم الحليب وهرمون الحليب \\
\hline
\end{tabular}




\begin{tabular}{|c|c|c|}
\hline غير معنوي & 0.32 & هرمون الحليب واللاكتوز \\
\hline$(\mathrm{p}<0.01)$ & 0.43 & هرمون الحليب والكولستيرول الكلي \\
\hline غير معنوي & 0.39 & هرمون الحليب والبروتين الكلي \\
\hline غير معنوي & 0.25 & الكلوكوز والكولستيرول الكلي \\
\hline غير معنوي & 0.09 & الكلوكوز والبروتين الكلي \\
\hline غير معنوي & 0.28 & الكولستيرول الكلي والبروتين الكلي \\
\hline
\end{tabular}

CONFLICT OF INTERESTS.

There are non-conflicts of interest.

[1] الزبيدي، عبد الاله عبد الله محمود.(2011). تأثير فترة الرضاعة المختلفة في بعض الصفات الفسلجية والإنتاجية لعجلات الفريزيان. مجلة ديإلى للعلوم الزراعية.3.(2): 591-585.

[2] حسن، ماجد ولي.( 2014). تأثير الدورة الإنتاجية والحمليليتر في إنتاج الحليب اليومي ومكوناته في أبقار vol.26,no الفريزيان، zanco journal of pure and applied Sciences

$$
\text { [3] هاموند، جون. كتاب حيوانات المزرعة، الدار العربية للنشر والتوزيع.(1985) • }
$$

[4] السامرائي، فراس رشيد عبد اللطيف ونصر, نوري خضير الانباري . (2010). التقييم الوراثي لإنتاج الحليب في الموسم الاول والمدة بين الولادتين الاولى في قطيع الهولشتاين. مجلة جامعة ذي قار. المجلد

$$
\text { .127- 121: :5 }
$$

[5] Dybus, A.; Grzesiak, W.; Kamieniecki, H.; Szatkowska, I.; Sobek.; Blaszczykm, P .; Czerniawska, E .; Zych, S. and Muszynska, M. (2005). Association of genetic variants of bovine prolactin with milk production traits of black and white and Jersey cattle. Arch. Anim. Breeding.48: 149-156.

[6] حنا، عزيز كبر وعطا الله, سعيد محمد. كتاب مبادئ إنتاج الحليب. دار الكتب للطباعة والنشر، جامعة الموصل، 1986.

[7] الاباغ، ازاد شمس الدين صالح والمززاني، إدريس عبدالله حمد أمين. (2010). دراسة بعض الصفات

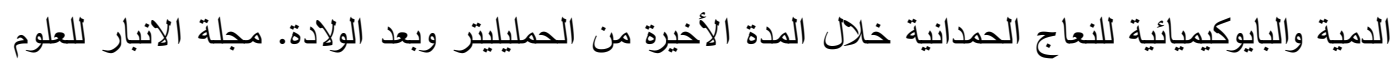

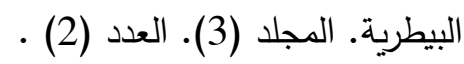

[8] Pollard, T.D. and Earnshaw, W.C. (2008). Cell biology. El Sevier publisher Second edition., 231-253.

[9] Gonzalez, F.H.D. and Rocha, J.A.R. (1998). Metabolic profile variations and reproduction performance in Holstein cows of different milk yields in Southern Brazil. Arq. Fac. Vet. UFRGS. Porto Alegre. V. 26. N. 1. 
[10] Haddadin, M.S.; Gammoh, S.I. and Robinson, R.K. (2008). Seasonal variations in the chemical composition of camel milk in Jordan. J. Dairy. Res., 75: $8-12$.

[11] SPSS Inc. (2002). Statistical Package for social Science version 11.5 for windows LEAD Technologies .Inc. USA.

[12] Duncan, D. B. (1955). Multiple Range and Multiple Test. Biometrics. 11:1-42.

[13] Banchero, G.E.; Clariget, R.; Bencini, R.; Lindsay, D.R.; Milton, J,B.; Martin,

G.B. (2006). Endocrine and metabolic factors involved in the effect of nutrition on production of colostrum in female sheep. Reproduction .nutr.dev.44-460.

[14] سلهب، سليمان وجورج حداد.(2012). كتاب فيزيولوجيا التتاسل. منشورات جامعة دمشق المجلس

$$
\text { الاعلى للمعاهد المتوسطة، المعهد التقاني الزراعي بدمشق. }
$$

[15] Ghung, E. R.; Rhim, T. J. and Han, S. K. (2000) . Association between PCR RELP markers of growth hormone and prolactin genes and production traits in dairy cattle. J. Anim. Sci. 38: 321-336.

[16] Marnet, P.G. and Negrao, J.A. (2000). The effect of a mixed management system on the release of oxytocin, prolactin and cortisol in ewes during suckling and machine milking. Repord. Nutr. Dev. 40: 271-281.

[17] Kappel,L.C.; Ingraham ,R.H.;M,E.B.;Zeringue,L.; WilsonD and Babcock, D.K.,(1983). Relationship between fertility and blood glucose and cholesterol concentration in holstein cows .Am.J.vet .res.45: 2607-2612.

[18] Azza, H.A.; Khalil, A. S.; EL-Hamamsy, H. T. and Ezzo, O. H. (2010). The effect of recombinant Bovine somatotropin administration on milk production, some hemato -biochemical parameters and reproductive performance of lactating cows. Global Veterinaria. 4: 366-373.

[19] الطائي, كاظم جهيد كاطع. (2006). دراسة التغيرات الدمية والفسلجية للأبقار والعجول الموجبة والسالبة

$$
\text { لاختبار السلين وعلاقتها بالإنتاج. أطروحة دكتوراه ـ كلية الزراعة. جامعة بغداد. }
$$

[20] Hafez, E.S.E.,(2000). Reproduction in farm animal. lippincott Williams and Wilkins, Philadelphia

[21] Nazifi, S.; Saeb, M. and Ghavami, S. M. (2002). Serum lipid profile in Iranian fat tailed sheep in late pregnancy at parturition and during the post parturition period. J. Vet. Med. Ser. A. 19: 9-12.

[22] Antunovic, Z.; Sencic, D.; Speranda, M. and Liker, B. (2002). Influence of the season and the reproductive status of ewes on blood parameters. Small uminant Research 45: 39-44. 
[23] محمود، كازان توفيقز. (2002) ـ تأثير بعض الهرمونات على الاداء التتاسلي وبعض التغيرات

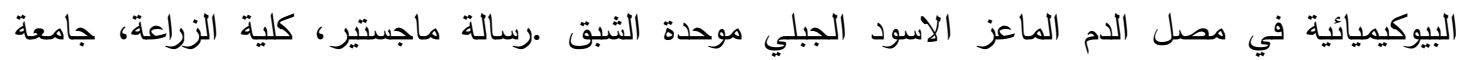

[24] Moallem, U.; Dahl, E.G.; Duffey, E.K.; Capuco, A. V.; Wood, D. L.; McLeod, K.; Baldwin, V. I. and Erdman, R. A. (2004) . Bovine somatotropin and rumen-undegradable protein effects in prepubertal dairy heifers: effects on body composition and organ and tissue weight. J. Dairy Sci. 87: 3869-3880.

[25] النعيمي، نادية عبد الهادي عبد الامير.(2000). تأثير الحمليليتر المتقدم وإنتاج الحليب في بعض

المؤشرات الفسلجية والدموية في ابقار الفريزيان ضمن الظروف المحلية والمعتدلة. رسالة ماجستير، كلية الطب

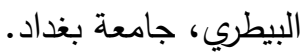

[26] القدسي، ناطق حميد وجيأل , فكتور ايليا .(2010). إنتاج ماشية الحليب. قسم الثروة الحيوانية، كلية

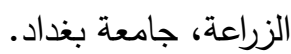

27] الدكاك، ماجد وآخرون .(2017). العوامليليتر المؤثرة في إنتاج حليب الموسم الاول والحياة الإنتاجية للابقار الشامية، المجلة الاردنية في العلوم الزراعية ، المجلد 13، العدد 3، 877-889. [28] جمعة, فاروق طيب. محمود, بختيار محمد. محمد, ايهان محمد. يوسف, ئاوات نور الدين.(2011). تأثير الولادة وإنتاج الحليب في بعض الصفات الدمية والكيموحيوية في الماعز الاسود الجبلي. مجلة العلوم الزراعية العراقية ( - (1-1).

[29] Chaiyabutr, N.; Boonsanit, D and Chanpongsang, S. (2010) . Effects of cooling and biochemical parameters at different stages of lection of crossbred Holstein Friesian cow in the Tropics. Asian-Aust. J. Anim. Sci. 2: 230-238.

[30] الربيعي، هاشم مهاي وهديل, علوان عبد وحيدر, رحيم عبيد (2015). دراسة علاقة بعض التغيرات

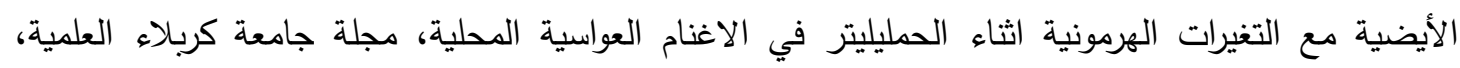

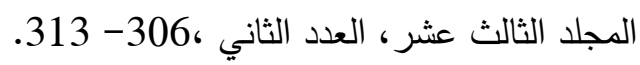

[31] De Vries, M. J. and Veerkamp, R.F. (2000) . Energy balance of dairy cattle in relation to milk production variable and fertility. J. Dairy Sci. 83: 62-69. 